\title{
Fires in Inclined Trenches: the Effects of Trench and Burner Geometry on the Critical Angle
}

\author{
P.J. WOODBURN' ${ }^{1}$ and D.D. DRYSDALE \\ Fire Safety Engineering Group \\ Department of Civil and Environmental Engineering \\ Edinburgh University \\ The King's Buildings \\ Edinburgh, EH9 3JN, UK
}

\begin{abstract}
The critical angle for flame deflection in fires in inclined trenches was determined using the Computational Fluid Dynamics (CFD) code FLOW3D. The trenches had rectangular cross-sections and contained rectangular burners which extended the full width of the trench. Both two and three-dimensional simulations were carried out. The flowfield was simulated transiently and allowed to develop towards a final steady state. The critical angle was independent of the heat release rate. The three-dimensional simulations gave critical angles close to those measured in experiments. The critical angle was dependent on the geometry of both the trench and the burner. Longer, thinner burners and / or higher trench walls reduced the critical angle towards the value of 10 degrees determined for two-dimensional simulations. Square trenches with square burners had a critical angle of approximately 25 degrees. The critical angle was dependent on the trench and burner geometries through their effect on the shape of the plume within the trench.
\end{abstract}

Keywords: Inclined trenches, critical angle, computational fluid dynamics, trench geometry, burner geometry.

\footnotetext{
${ }^{1}$ Now at: Mechanical Engineering Department, Imperial College, Exhibibition Road, London SW7 2BX, U.K.
} 


\section{Introduction}

The fire at the King's Cross Underground Station provided the motivation for several recent projects investigating the dynamics of fires in inclined trenches. This paper reports the application of Computational Fluid Dynamics (CFD) techniques to this scenario. This work was part of a project funded by the Health and Safety Executive which was initiated as a direct result of the King's Cross fire. The first part of this project investigated the critical angle using small-scale experiments [1]. The motivation for using CFD simulations was to allow many more trench and burner configurations to be studied than would be possible using experiments. At the same time, it was necessary to test the CFD results against a set of carefully controlled experiments.

\section{Previous research}

Before the King's Cross fire there was little information about the behaviour of flames in inclined trenches. De Ris and Orloff observed different flame behaviour between flames on burners in horizontal trenches and those in trenches inclined steeper than approximately 15 degrees [2].

The public enquiry into the King's Cross fire concluded that the flame spread on the combustible surfaces of the escalator had been so rapid that it allowed little time for escape [3]. Computational Fluid Dynamics (CFD) simulations carried out as part of the investigation showed the first evidence of the so called 'trench effect' [4] [5]. Experiments [6] [7] [8] demonstrated that the plume from a fire in a trench attached to the trench rather than rising vertically away from it if the trench was inclined at an angle greater than a critical angle $\theta_{c}$. $\theta_{c}$ was found to be less than 30 degrees. Cox et al had previously noted the possiblility of two distinct stable flow regimes under these conditions [9].

Subsequent research included Smith's measurements of the flame lengths of both attached and unattached plumes for a variety of burning scenarios [10], which clearly showed two different flow types dependent on the trench inclination. Smith measured the critical angle for a square burner in the floor of a square trench as 27 degrees. Wu [1] measured the critical angle for two different experimental trenches to within two degrees. Both Smith and $\mathrm{Wu}$ found that the critical angle was independent of the heat input rate for heat input rates $\dot{Q}>280 \mathrm{~kW} / \mathrm{m}^{2}$. Atkinson and $\mathrm{Wu}$ also investigated the transient behaviour of an attached plume [11].

Drysdale and Macmillan [12] measured the rate of flame spread on inclined PMMA slabs, with and without sidewalls. With the side walls in place, there was an increasingly sharp increase in the rate of flame spread at the critical angle as the sample width was widened. For a sample width of $60 \mathrm{~mm}$ with $20 \mathrm{~mm}$ high walls the critical angle was between 10 and 15 degrees.

\section{Approach}

The experiments listed above demonstrated that a different type of flow is established in trenches which are inclined at angles steeper than some critical value. This flow causes a 
large increase in the rate of flame spread over combustible surfaces within the trench. The present research had two objectives. Firstly, to assess the accuracy of CFD simulations of fires in inclined trenches through simulations of previous experiments. Secondly, to investigate the effects of many different trench and burner geometries on the critical angle, and through this to gain a deeper understanding of the dynamics of this type of scenario.

Both two and three-dimensional simulations were carried out, using the FLOW3D code [5]. The two-dimensional case corresponds to the case of an infinitely wide trench, which is similar to an infinitely long burner on an infinitely wide plane. The layout for the threedimensional simulations is shown in figure 1.

side and top boundaries, atmospheric pressure set

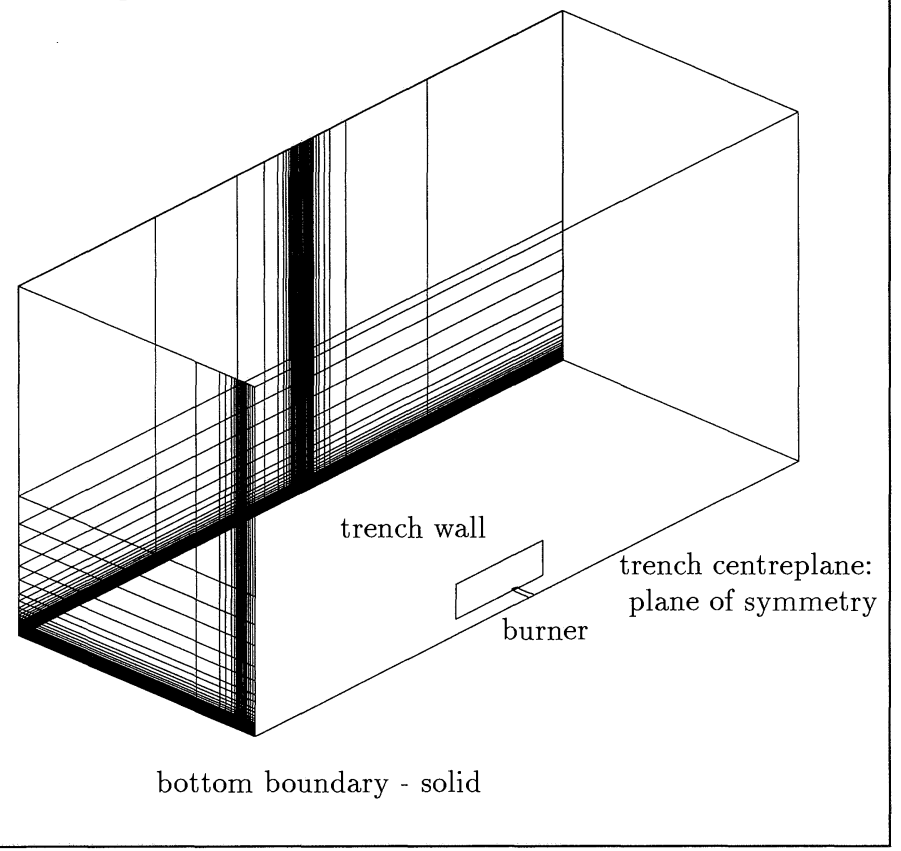

Figure 1: Configuration for the three-dimensional simulations. The trench wall extended normally from the solid floor. The dimensions of the domain were $10 \mathrm{~m} \times 5 \mathrm{~m} \times 4 \mathrm{~m}$ in the longitudinal, vertical and cross-trench directions. The domain contained $41 \times 23 \times 15$ cells of which $35 \times 12 \times 7$ were within the trench. 
The conditions used in the simulations were:

1. Only half the trench was simulated, a symmetry condition was imposed on the trench centreplane.

2. All other boundaries except for the lower plane had atmospheric pressure specified. The bottom boundary was specified as a wall.

3. In all simulations the grid expanded away from the region around the burner. In the area around the burner the grid spacing was regular.

4. The computational domain in the two-dimensional simulations had dimensions $30 \mathrm{~m}$ horizontally and $20 \mathrm{~m}$ vertically with the burner positioned at the center of the bottom plane. The grid contained $53 \times 36=1908$ cells.

5. The computational area for the three-dimensional simulations had the following dimensions in meters: $-5 \leq X \leq 5,0 \leq Y \leq 5,0 \leq Z \leq 4$. There were $41 \times 23 \times$ 17 grid cells in the $\mathrm{X}$ (along trench), $\mathrm{Y}$ (normal to trench floor), $\mathrm{Z}$ (across trench) directions respectively, a total of 16031 cells. The trench contained $35 \times 12 \times 8$ grid cells.

6. The trench wall was simulated using an infinitely thin surface, with zero heat flux to this surface.

7. The burner extended across the full width of the trench in all simulations.

8. The eddy break-up combustion model was used. The fuel was given the thermal and combustion properties of propane, the fuel used in Wu's experiments [1]. The fuel flowrate per unit burner area gave a heat output per unit burner area of at least $300 \mathrm{~kW} / \mathrm{m}^{2}$.

9. The fuel flow rate was increased linearly over the first 3 seconds of the simulation. Each simulation was carried on for at least a further 15 seconds or until conditions in the area around the burner were steady.

10. The simulations were transient using initial timesteps of $0.01 \mathrm{~s}$ which increased to $0.2 \mathrm{~s}$ by the end of the simulation. Variations in the size of the timesteps around these values were found not to have a significant effect on the simulation results.

11. A 'hybrid' differencing scheme for convection (first order accurate) was used for all the variables except pressure for which central differencing was used. Simulations with second-order (higher upwind) and third-order (Quick) upwind schemes did not show significant differences in results.

12. The $k-\varepsilon$ turbulence model was used. This model gives good results for planar plumes [13] and was therefore appropriate for use in simulations of this scenario. 
13. The trench floor was specified either as constant temperature, allowing heat transfer, or as adiabatic in which case no heat was transferred to it. The heat transfer condition at the trench floor was found not to have a noticeable effect on the critical angle.

14. CPU times on a SUN SPARC 10 were approximately 2 hours for the $2 \mathrm{D}$ case, and 10 hours for the $3 \mathrm{D}$ case.

\section{Results}

In all the simulations the initial plume was vertical. At trench inclinations steeper than the critical angle the plume was subsequently deflected towards the trench until it became attached to the trench floor, this process is shown in figure 2. This sequence was also observed in Wu's experiments.

The transition from steady-state vertical plume to steady-state attached plume took place over a change in inclination of less than one degree, as illustrated by figures 3 and 4 which show the flowfields in simulations of Wu's experiments with a $0.276 \mathrm{~m}$ square trench inclined at 19 and 20 degrees. The only difference between the two simulations was the inclination of the trench. In terms of flame spread, this represents a change from countercurrent to concurrent spread.

Comparison of the critical angles obtained from simulations of Wu's trenches with the experimental critical angles is shown in table 1. The simulations gave critical angles close to the experimental measurements. The critical angle for the $0.09 \mathrm{~m}$ trench was not evaluated any more accurately than shown in figure 1 . Wu's experiments did show some plume deflection towards the trench at inclinations up to 3 degrees less than the critical angle which were not seen in the simulations. However the critical angle, at which the plume is fully attached to the trench was well reproduced.

\begin{tabular}{||c|c|c||}
\hline \hline & $\begin{array}{c}\text { Critical angle for } \\
\text { Wu's 0.276m trench } \\
\text { (degrees) }\end{array}$ & $\begin{array}{c}\text { Critical angle for } \\
\text { Wu's 0.09m trench } \\
\text { (degrees) }\end{array}$ \\
\hline Experiments & 20 & 27 \\
\hline Simulations & 20 & $24<\theta_{c}<28$ \\
\hline \hline
\end{tabular}

Table 1: Comparison of critical angles for Wu's experiments and present simulations

The critical angle was found to be independent of the heat input rate, which agreed with the experiments of both $\mathrm{Wu}[1]$ and Smith [10]. The grid independence of the solutions 

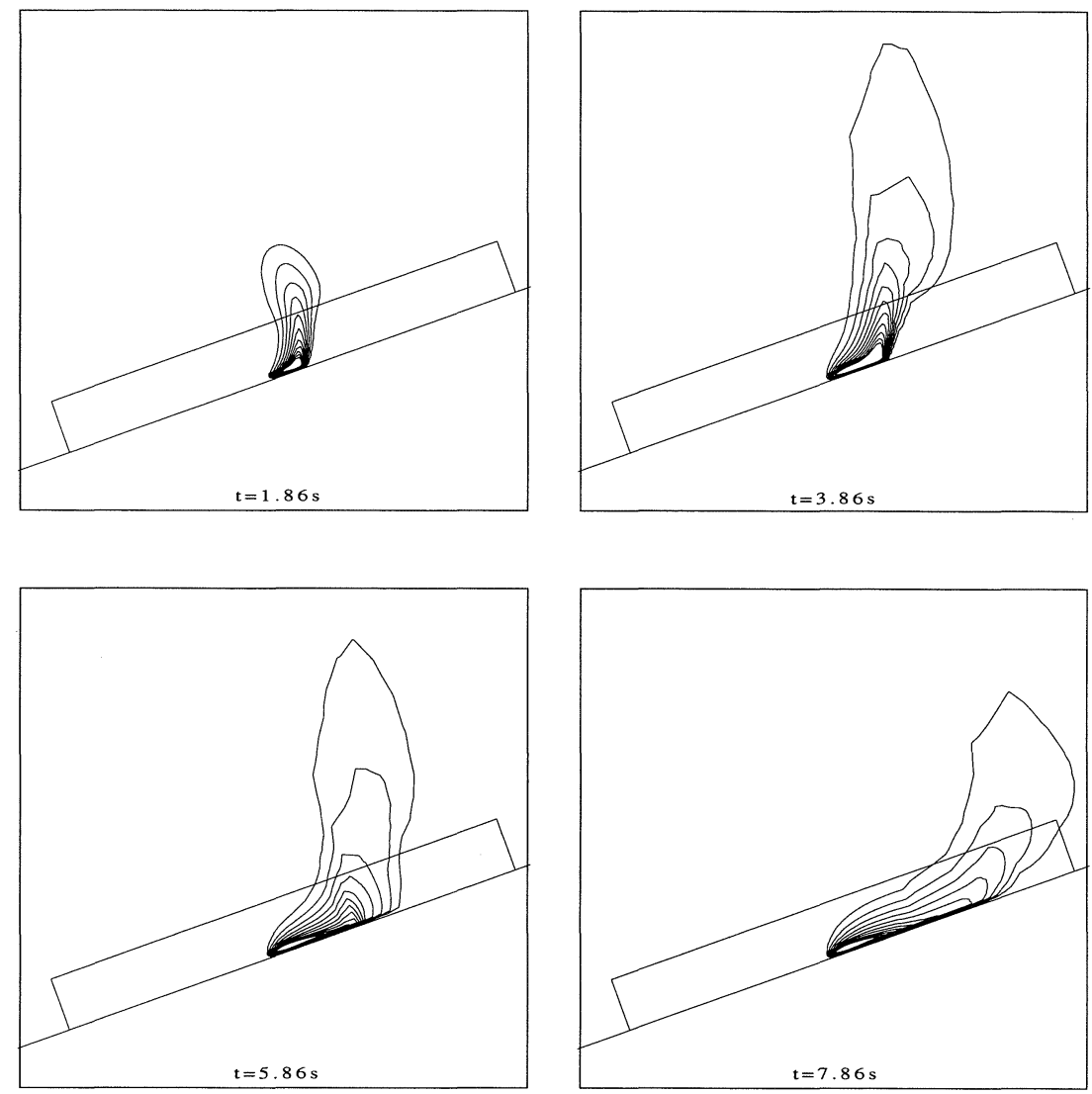

Figure 2: The development of the plume in the $0.275 \mathrm{~m}$ wide trench at an inclination of 20 degrees. Contours of temperature $(350 \mathrm{~K}-850 \mathrm{~K}$ by $50 \mathrm{~K})$ on the trench centreplane. The initial plume rose vertically away from the trench floor. Subsequent imbalances in the entrainment into each side of the plume within the trench caused the deflection of the plume into the trench.

was tested using grids twice as fine as the grids detailed above for both two and threedimensional simulations. Neither case showed a significant difference in results using the finer grid. 


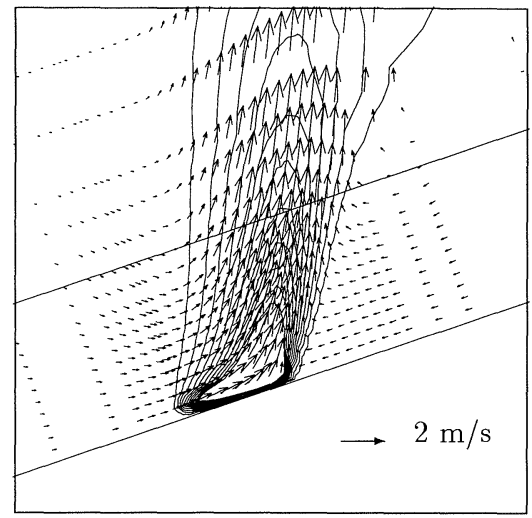

Figure 3: Velocity vectors and temperature contours on centreline of $0.27 \mathrm{~m}$ wide trench at 19 degrees inclination. Contours $350 \mathrm{~K}$ to $850 \mathrm{~K}$ by $50 \mathrm{~K}$. The straight line across the middle of the flow is the top of the trench.

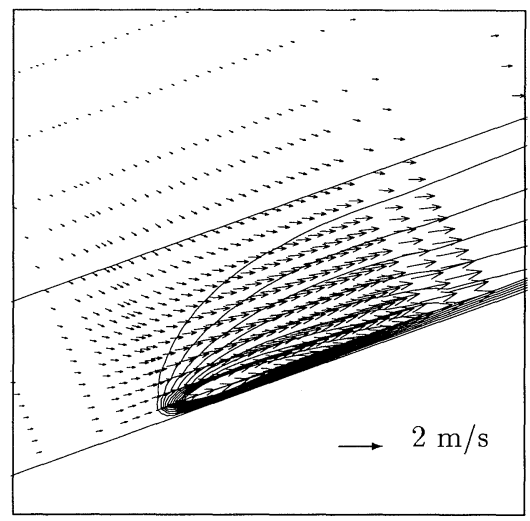

Figure 4: Velocity vectors and temperature contours on centreline of $0.27 \mathrm{~m}$ wide trench at 20 degrees inclination. Contours $350 \mathrm{~K}$ to $850 \mathrm{~K}$ by $50 \mathrm{~K}$.

\section{Two-dimensional simulations}

The critical angle for the two-dimensional simulations was 10 degrees. As with the threedimensional results, the transition at the critical angle took place over a change in incli- 
nation of less than one degree, in this case between 9 and 10 degrees.

There are no data available for long sources on wide inclined planes, however Drysdale and Macmillan's flame spread rate measurements on their widest sample indicate a critical angle of between 10 and 15 degrees. Given that the flow in this case was only approximately two-dimensional, these data are not inconsistent with these simulations.

\section{Burner geometry}

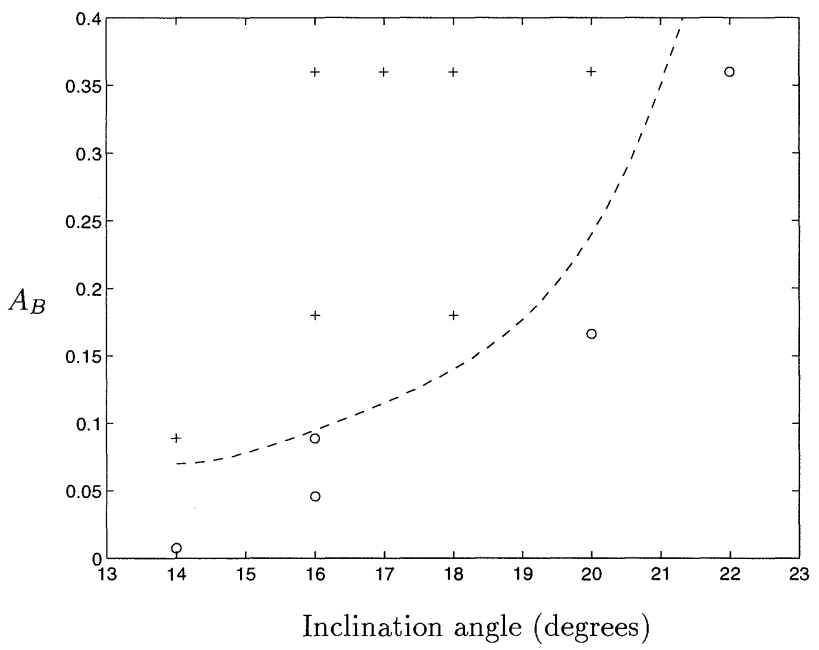

Figure 5: The effect of the burner aspect ratio $A_{B}=\frac{B}{W}$ on the flow regime for fixed trench aspect ratio $A_{T}=0.48$. Legend: o: plume attached to trench; +: plume vertical; - - - : approximate boundary between the two regimes.

The burner geometry was characterised by the burner aspect ratio, the ratio of the width of the burner (in the along trench direction since this was the thinner direction for the majority of burners) to the width of the trench $A_{B}=\frac{B}{W}$, where $\mathrm{B}$ is the width of the burner and $\mathrm{W}$ is the width of the trench.

The effects of the burner geometry are shown in figure 5. With reducing burner aspect ratio $A_{B} \rightarrow 0$ the critical angle reduced. For very thin burners the critical angle reduced towards the two-dimensional value of 10 degrees. Smith's critical angle for a square burner $\left(A_{B}=1.0\right)$ in a square trench was 27 degrees. It was clear from the simulations that as the burner got wider and thinner $A_{B} \rightarrow 0$ the flow over the burner became more closely two-dimensional especially in the region of the middle of the trench. 


\section{Trench geometry}

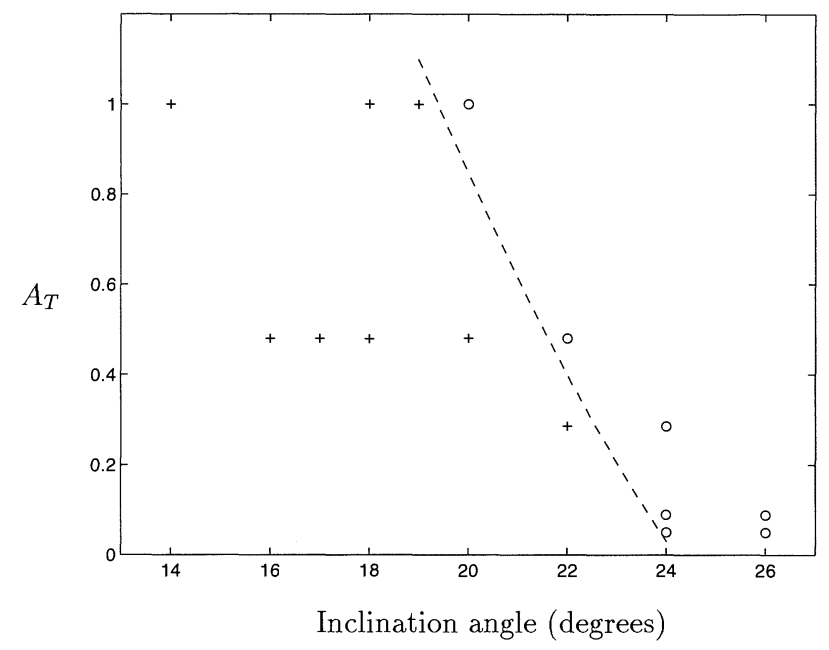

Figure 6: The effect of the trench aspect ratio $A_{T}=\frac{H}{W}$ on the flow regime for $A_{B}=0.37$. Legend: o: plume attached to trench; +: plume vertical; - . - - approximate boundary between the two regimes.

The trench geometry was characterised by the trench aspect ratio, the ratio of the trench height to its width, $A_{T}=\frac{H}{W}$, where $\mathrm{H}$ is the height of the trench. The effects of trench geometry over most of the range of trench heights investigated here were less pronounced than the effects of the burner geometry, but increasing $T$ reduced the critical angle, figure 6 . Increasing the trench height made the flow around the burner more nearly twodimensional.

An extreme example of the effect of the trench aspect ratio was shown in simulations of a square burner on an inclined plane, which is effectively a burner in a trench with $A_{B}=1.0$ and $A_{T}=0$. In this case, the critical angle at which the plume attached to the plane was steeper than 60 degrees. This agrees with Ito and Kashiwagi's observations of flame spread on inclined PMMA sheets [14]; with a source of $A_{B} \approx 1$, the flame in their experiment did not attach to the sheet except at sheet inclinations close to vertical.

\section{Discussion}

From both experimental observations and the time-dependent CFD simulations shown in figure 2 , the mechanism of plume attachment to the trench floor is as follows. The 

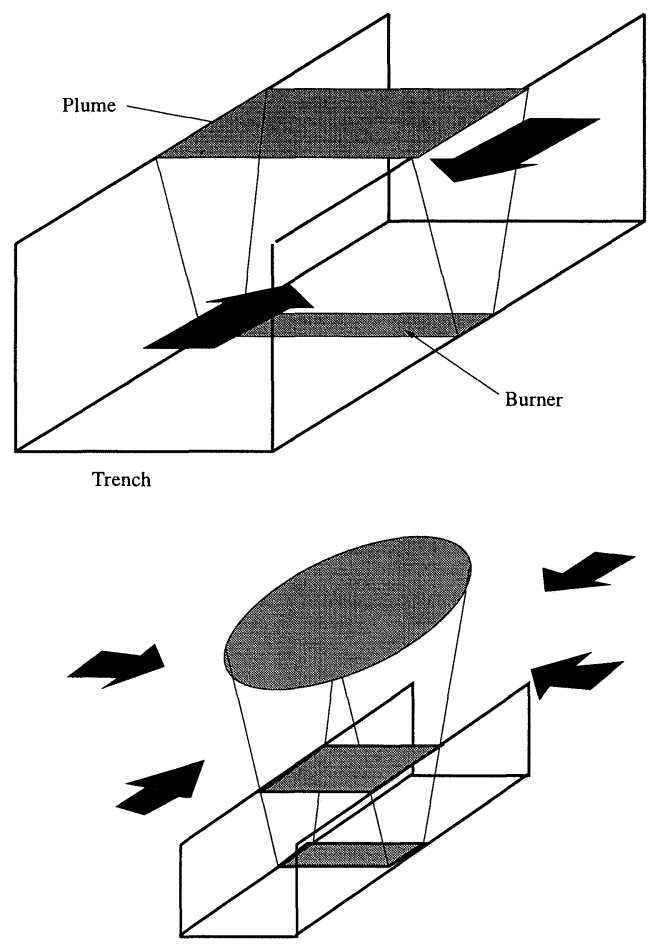

Figure 7: The two regions of the plume. Top diagram: within the trench, entrainment into the plume is possible from only two directions, either way along the trench. Bottom diagram: above the trench entrainment is possible from all directions. Large imbalances in the entrainment of air into the plume are much less likely in the region above the trench.

initial plume formed is vertical. Subsequent imbalances in the momentum of the ambient fluid entrained into the plume due to the proximity of the upper section of the trench cause deflection of the plume towards the trench. The deflection of the plume causes a greater imbalance and the plume attaches to the floor of the trench where its position is maintained by entrainment into upper side of the plume.

In the preceding section it was noted that the critical angle was dependent on the burner 
aspect ratio $A_{B}$ and the trench aspect ratio $A_{T}$. As the trench became wider and higher, and the resulting flow within it began to approximate two-dimensional behaviour, the critical angle reduced towards the figure found for the infinitely wide trench, simulated using two-dimensions only, which was 10 degrees. This dependence on trench and burner geometry is supported by the available experimental data.

The evidence indicates two things. Firstly, conditions below the level of the top of the trench walls determine the critical angle. Above the top of the walls entrainment of ambient fluid is omni-directional and in the absence of overall ambient fluid movement there is negligible deflection of the plume. Below the top of the trench walls the entrainment only occurs from either direction along the trench. In this case imbalances in momentum entrained from each direction affect all the momentum entrained into the plume and are therefore likely to cause significant deflection of the plume. The difference between the two regions of the plume is shown in figure 7 .

The critical angle depends on how closely the flow in the region below the top of the trench walls approaches two-dimensional flow. For approximately two-dimensional plumes, entrainment only occurs from the two directions perpendicular to the plume centreplane, and any imbalance in entrainment between these two sides has a much greater effect that imbalances in entrainment into a free, round plume. Therefore, the greater the proportion of the flow which is approximately two-dimensional, the lower the critical angle. The flow becomes more two-dimensional with decreasing $A_{B}$ and/or increasing $A_{T}$.

\section{Conclusions}

CFD simulations using FLOW3D of fires in inclined trenches gave critical angles which agreed well with the available experimental data. The critical angle for a fire in an inclined trench was dependent on both the geometry of the burner and the geometry of the trench. Longer, thinner burners with high trench walls produce plumes within the trench which are approximately two-dimensional, especially in the middle of the trench. As plumes tend towards two-dimensional flow, the critical angle tends towards the value measured in two-dimensional simulations which was 10 degrees. In contrast, plumes formed from square burners in square trenches have critical angles of approximately 25 degrees. The critical angle is therefore dependent on the shape of the plume within the trench.

\section{Acknowledgements}

This work was funded by the Health and Safety Laboratory, Health and Safety Executive, Harpur Hill, Buxton, Derbys. UK. The authors would like to thank Dr Stuart Jagger and Dr Chris Lea from the HSE for their support of this project.

\section{References}

[1] Y. Wu and D. D. Drysdale. Upward flame spread on inclined surfaces. Technical report, Fire Safety Engineering group, Civil and Environmental Engineering Dept. 
Edinburgh University, 1994. Final report to the H.S.E.

[2] J. De Ris and L. Orloff. The role of buoyancy direction and radiation in turbulent diffusion flames on surfaces. In 15th International Symposium on Combustion, 1974.

[3] D. Fennel. Investigation into the King's Cross fire. Technical report, H.M.S.O., 1988.

[4] S. Simcox, N. S. Wilkes, and I. P. Jones. Fire at King's Cross underground station 18th Nov 1987: Numerical simulation of the buoyant flow and heat transfer. Technical report, AERE Harwell, 1988.

[5] S. Simcox, N. S. Wilkes, and I. P. Jones. Computer simulation of the flows of hot gases from the fire at King's Cross Underground Station. Fire Safety Journal, 18:49-73, 1992.

[6] K. Moodie and S. F. Jagger. Results and analysis from the scale model tests. In I.Mech.E. Seminar: The Kings Cross Underground Fire: Fire Dynamics and the Organisation of Safety, 1989.

[7] K. Moodie and S. F. Jagger. The technical investigation of of the fire at London's King's Cross Underground Station. J. of Fire Prot. Engr., 3:49-63, 1991.

[8] D. D. Drysdale, A. J. R. Macmillan, and D. Shillito. The King's Cross fire: experimental validation of the trench effect. Fire Safety Journal, pages 75-82, 1992.

[9] G. Cox, R. Chitty, and S. Kumar. Fire modelling and the King's Cross fire investigation. Fire Safety Journal, 15:103-106, 1989. Letter to the editor.

[10] D. A. Smith. Measurements of flame length and flame angle in an inclined trench. Fire Safety Journal, 18:231-244, 1992.

[11] G. T. Atkinson, Y. Wu, and D. D. Drysdale. Fire driven flow in an inclined trench. Fire Safety Journal, 25:141-158, 1995.

[12] D. D. Drysdale and A. J. R. Macmillan. Flame spread on inclined surfaces. Fire Safety Journal, pages 245-254, 1992.

[13] W. Rodi. Turbulent buoyant jets and plumes. HMT. Pergamon, 1983.

[14] A.Ito and T. Kashiwagi. Characterization of flame spread over PMMA using holographic interferometry sample orientation effects. Combustion and Flame, 71:189204, 1988. 